\title{
Patron Survey of Acceptable Wait Times at Transit Bus Stops in the District of Columbia
}

\author{
Stephen A. Arhin, P. E. PTOE, Adam Gatiba, Melissa Anderson, Melkamsew Ribbisso, \\ Babin Manandhar
}

Howard University Transportation Research Center, NW, Washington, DC, USA

Email: saarhin@howard.edu

How to cite this paper: Arhin, S.A., PTOE, P.E., Gatiba, A., Anderson, M., Ribbisso, M. and Manandhar, B. (2019) Patron Survey of Acceptable Wait Times at Transit Bus Stops in the District of Columbia. Open Journal of Civil Engineering, 9, 268-280. https://doi.org/10.4236/ojce.2019.94019

Received: September 7, 2019

Accepted: October 18, 2019

Published: October 21, 2019

Copyright $\odot 2019$ by author(s) and Scientific Research Publishing Inc. This work is licensed under the Creative Commons Attribution International License (CC BY 4.0).

http://creativecommons.org/licenses/by/4.0/

\begin{abstract}
The wait time of bus patrons at bus stops is one of several measures for assessing reliability of transit services, especially in urban areas. The uncertainty associated with waiting affects bus patrons' perception of quality of the service provided. Studies in this subject area have therefore been of interest to transit service agencies and officials. This paper presents the findings of a study conducted to determine patrons' maximum acceptable wait times (beyond the scheduled arrival time) at bus stops in an urban area. In all, 3387 bus patrons at 71 selected bus stops were surveyed over a period of 9 months. The results of the survey showed that the least acceptable wait time beyond the scheduled arrival time was 1 minute, while the maximum acceptable wait time was reported to be 20 minutes. Also, only one-third (33\%) of the total number of patrons surveyed were willing to wait up to 5 minutes beyond the scheduled arrival time of buses. In addition, patrons are willing to wait longer in warm weather. On average, white patrons were found to have the least maximum acceptable wait times, followed by Hispanics, Asians, and then Blacks.
\end{abstract}

\section{Keywords}

Acceptable Wait Time, Bus Patrons, District of Columbia

\section{Introduction}

Urban areas typically have several modes of transportation, including bus transit. Transit buses offer short distance transportation between bus stops on different routes, especially in dense urban areas. Transit agencies aim at keeping patrons satisfied by improving on-time arrivals at bus stops and reducing passenger wait times. Bus transit travel time and wait times are two of the critical 
factors that influence patrons' decision to use one mode of transportation over another. If transit buses arrive at scheduled times, patrons are less likely to have the need to find alternative mode(s) of transportation. However, if buses are chronically late at bus stops, patrons may feel that the bus system is unreliable and may most likely seek alternative modes of transportation.

Several studies have also shown that patrons waiting at a bus stop perceive wait time to be three times more bothersome than the time spent riding on the bus. Consequently, travelers are more likely to change their initial transportation mode choice to another in order to decrease their wait time. It is therefore necessary to be able to determine the maximum acceptable wait time of patrons in order to identify appropriate bus headways, reduce dwell times, and provide adequate allocation of bus stops along a route. This study aimed at determining patrons' maximum acceptable wait times beyond the schedule arrival time at bus stops in Washington, DC.

\subsection{Perceived and Actual Waiting Times}

Several studies have determined that waiting at bus stops is one of the most onerous components of using bus transit services. The results of a survey on bus user preferences conducted in Australia showed that, among factors such as vehicle quality, trip quality and information quality, waiting time was the top most concerns of patrons [1]. The time patrons spend waiting at a bus stop is perceived to be more burdensome than the time spent in-vehicle. Also, the uncertainty associated with waiting is attributed as the source of discomfort experienced by patrons [2]. Inconsistencies in waiting times inevitably lead to large variabilities in travel time. A study found that waiting time was a significant factor in explaining travel time variability [3]. In addition, review of literature revealed that perceived wait time of passengers differs from their actual wait times. Bus patrons subjectively overestimate their actual wait times and place more value on this perceived wait time more than any other components of their trip. Perceived wait time tends to dictate rider discomfort and preference towards bus services compared to actual wait time. A study was conducted to estimate the relationship between perceived and actual waiting times of patrons at bus stops on the campus of Ohio State University [4]. The mean difference between the perceived and actual waiting time of passengers was estimated to be $0.84 \mathrm{mi}$ nutes. A valuation of wait time and service headway among some public transport users in the United Kingdom found that patrons perceive a minute of waiting at a bus stop to be equivalent to 4.4 minutes of in-vehicle time [5]. Also, it was determined that a minute of wait time is perceived as equivalent to $8.4 \mathrm{mi}-$ nutes of in-vehicle time for a 30-minute journey and equivalent to 13 minutes for a 45 minutes journey [6].

\subsection{Factors Affecting Wait Time Perception}

\subsubsection{Bus Stop Features and Surroundings}

Bus stop features such as shelter, bench, lighting, presence of security and com- 
fort affect the perceived wait times of patrons. A study showed that transit users in Grenoble (in France) overestimated their actual wait times at bus stops where light and heat/ventilation where absent [7]. Also, lighting, music and aesthetics influenced the perceptions of waiting time. Transit users of a Dutch railway service generally preferred bright lighting, calming music and warm colors [8]. A study compared transit riders' actual and self-reported waiting times at 36 bus stations in the cities of Minneapolis and St. Paul (in Minnesota). The study concluded that wait times at bus stops without amenities such as shelter and bench are perceived to be about 1.3 times more than they actually are. In addition, with respect to security of the surroundings, females who waited at insecure bus stops for more than 10 minutes overestimated their waiting times as compared to their male counterparts [9].

\subsubsection{Period of Day}

The time of day during which a passenger's wait time for the arrival of a bus at a bus stops has been determined to affect perceived wait times. Perceived and actual wait times are longer during the afternoon than the evening and morning. However, the ratio of perceived to actual wait times is highest during the morning. Patrons tend to overestimate their waits at bus stop by a factor of 1.74 during the morning, by a factor of 1.63 during the afternoon and by a factor of 1.41 during the evening. The anxiety of getting to work on time during the morning explained the high morning period ratio [10]. Another study conducted in China also revealed that the period of day is a significant predictor of waiting time [11].

\subsubsection{Trip Purpose}

Among trip purposes such as personal, education, entertainment, shopping, returning home, patrons waiting for the arrival of a bus to travel to work are most likely to overestimate their waiting times. Psarros et al. (2011) estimated that patrons traveling for work purposes overestimate their wait times by a factor of about 1.3 [10]. Feng et al. (2015) showed that the trip purpose is a significant predictor of perceived wait time [11]. The findings in this study followed the conclusions of Psarros et al. (2011) in that passengers traveling for work purposes overestimated their waiting time the most.

\subsubsection{Transit Service Attributes}

The effects of factors such as service frequency and reliability on waiting times of transit users were considered in a study. It was determined that strict conformance to bus schedule allows transit users to coordinate their arrivals with those of the bus. This results in average wait times that are less than half the scheduled headway. Thus, uncertainty regarding the arrival times of buses due to unreliability increases the perceived wait time of transit users [12].

\subsubsection{Patrons' Demographics}

Psarros et al. (2011) revealed that male patrons tend to overestimate their wait 
times by a factor of 1.61 compared to female patrons who overestimate their wait times by a factor of 1.52 [10]. However, gender was determined not to be a significant predictor of wait time [11] [13].

\subsubsection{Weather Condition}

Stover et al. (2012) investigated the effects of wind, temperature, rain, and snow on bus ridership in Pierce County, Washington. The results showed that high winds, rain, and colder temperatures negatively affected bus ridership [14].

\subsection{Wait Time and Alternate Mode Choice}

Passengers have the tendency of considering other mode choices when their waiting time exceeds their threshold. This leads to a decrease in user confidence and ultimately a reduction in ridership. Chen et al. revealed that a variation in waiting time for transit users leads to selection of different mode choices. Travel time has always been known to be the lead factor is mode choice of commuters [15]; however, reliability, which is influenced by the consistency of wait time, is also a major factor of mode choices [16]. Also, a study was conducted on passengers' travel mode choice behavior when waiting at bus stations in Jinan City, China [17]. The study argues that passengers choose to end the waiting process and find a different mode choice when they reach a state of psychological imbalance due delay of bus arrivals. A similar study conducted in China, revealed that other mode choice options considered by passengers range from transferring to another bus route to other travel modes such as taxi and carpool [18]. Travel mode choice behavior is a consumer choice attribute. Thus, the individual characteristics of passengers determine their waiting time threshold and mode choice. Individual characteristics such as gender, level of education, occupation, and cultural differences determine what alternate mode of transport to choose beyond their acceptable waiting time [19].

\section{Methodology}

\subsection{Description of the Study Jurisdiction}

This study is based on data obtained in Washington, D.C. The city is divided into four quadrants of unequal area: Northwest (NW), Northeast (NE), Southeast (SE), and Southwest (SW). As of 2017, the population of Washington, D.C. was approximately 694,000 with an annual growth rate of approximately $1.41 \%$. The City is highly urbanized and is ranked as the sixth most congested city in the United States with each driver spending an average of 63 hours per year in traffic. The Washington Metropolitan Area Transit Authority (WMATA) is the agency that oversees the operations of Metrobus service in the jurisdiction. WMATA has a bus fleet of 1595 buses that make more than 400,000 trips each weekday. These buses serve about 11,500 bus stops and operate on 325 routes in Washington D.C., in portions of Maryland, and Northern Virginia, covering a total land area of about 1500 square miles. Of the total number of bus stops, 2556 (22.2\%) have shelters, while the remainder does not. 


\subsection{Selection of Bus Stops}

The study identified seventy-one (71) bus stops in the District of Columbia at which bus operational and survey data were collected. Two main types of bus stops were considered: bus stops with shelter and those without shelter. The bus stops were selected based on the following criteria:

1) Those on bus routes with longer headways: bus stops on routes with longer headways were selected to ensure that data collection technicians were able to complete the survey of bus-patrons before the arrival of a bus. Such bus stops were identified using the published timetables available on Washington Metropolitan Area Transit Authority's (WMATA) website.

2) Bus stops with high patronage: selection of bus stops with high patronage ensured that the required minimum numbers of patrons were surveyed at each bus stop.

3) Proximity to metro rail station: bus stops in proximity to railways are viable locations to have access to bus patrons with varying characteristics. In addition, such locations usually have a high number of bus patrons waiting to board a bus.

4) Roadway functional classification: bus stops on arterial and collector roads were selected for this study since they usually serve more than two bus lines.

Data collection at the selected bus stops was conducted over a nine-month duration from May 2018 through January 2019. Data was collected during the AM peak (7:00 AM - 9:30 AM), PM Peak (4:00 PM - 6:30 PM) and mid-day periods (10:00 $\mathrm{AM}-2: 30 \mathrm{PM})$.

\subsection{Survey Data Collection}

Passengers waiting for the arrival of the next bus at the selected bus stops were randomly selected and interviewed during the morning, evening and mid-day periods from Monday to Friday. The field technicians conducted the survey by use of electronic forms on computer tablets. The survey procedure was conducted as follows:

1) Upon arrival at the bus stop, the interviewer first obtained the temperature at the bus stop location from the National Oceanic and Atmospheric Administration (NOAA) weather service website and recorded it in the designated field on the form (or questionnaire) accordingly. In addition, the date of survey and the name of the interviewer were recorded.

2) The availability of bus stop amenities (shelter) recorded.

3) When a patron arrived at the bus stop, his/her arrival time and gender were recorded.

4) The field technicians then approached "willing" patron(s) and asked the following questions to complete the survey:

a) Whether the passenger was aware of the bus's arrival time.

b) At bus stops that serve more than one line, the patron was asked which route he/she intended to take. Where the bus stop served only one line, such information is obtained from the bus stop signpost. 
c) The maximum acceptable wait time beyond which the patron would consider an alternative transportation mode was also inquired and recorded.

d) What alternate mode(s) of transportation the patron would consider if the bus delayed beyond their maximum acceptable wait time was also posed and recorded.

5) The bus line(s) that serve the bus stop were recorded.

A total of 3387 patrons were surveyed over the period of the study. In the event that the minimum number of responses were not obtained during a particular peak period due to inclement weather or low sample, additional patrons were surveyed on the same day and peak period the following week.

\section{Results}

\subsection{Summary Survey Statistics}

Table 1 presents a summary of the characteristics of patrons and locations surveyed in this study.

The following section presents the descriptive statistics for the surveys conducted at the 71 selected bus stops in the District of Columbia. The patrons' characteristics analysed included gender, ethnicity, arrival time to the bus stop, knowledge of the bus arrival time to the bus stop, maximum acceptable wait time, and choice of alternative mode of transportation. The location characteristics included presence of bench at bus stop and temperature.

The analysis focused on the following:

a) Temporal: patron's time of arrival at the bus stop and period of the day.

b) Location characteristics: Bus Stop Type and Temperature.

c) Patron's Characteristics: gender, ethnicity, and patron's knowledge of bus arrival time.

d) Patron's choice: alternative mode of transportation.

\subsection{Acceptable Wait Times by Time of the Day}

Table 2 presents the number of patrons per maximum acceptable wait times by time of the day. From Table 2, majority of patrons' maximum acceptable wait time ranged between 5 to 10 minutes. Also, it can be observed that patrons tended to indicate shorter acceptable wait times during the evening and morning periods compared to the mid-day period, when patrons chose longer acceptable wait times.

\subsection{Acceptable Wait Times by Time by Hour of Day}

Table 3 presents the maximum acceptable wait times for patrons by hour of the day. From the table, the highest number of patrons chose 5 and 7 minutes as the maximum acceptable wait times during the morning hours (7:00 AM to 9:00 $\mathrm{AM}$ ) and evening hours (4:00 PM to 6:00 PM). Also, the majority of patrons chose 10 and 12 minutes as the maximum acceptable wait times during the mid-day hours (10:00 AM to 2:00 PM). 
Table 1. Survey statistics quick facts.

\begin{tabular}{cc}
\hline Total \# of patrons surveyed & 3387 \\
\hline Total \# of females & 1753 \\
Total \# of males & 1635 \\
Total \# of White patrons & 778 \\
Total \# of Black patrons & 771 \\
Total \# of Hispanic patrons & 747 \\
Total \# of Asian patrons & 545 \\
Total \# of “Other" patrons & 546 \\
Total \# of Locations surveyed & 71 \\
Total \# of Locations with Shelter & 40 \\
Total \# of Locations without Shelter & 31 \\
\hline
\end{tabular}

Table 2. Patron's maximum acceptable wait times by time of the day.

\begin{tabular}{cccc}
\hline \multirow{2}{*}{ \# Minutes } & \multicolumn{3}{c}{ Time of Day } \\
\cline { 2 - 4 } & AM & MID & PM \\
\hline 2 & 2 & 0 & 0 \\
3 & 13 & 3 & 16 \\
5 & 409 & 121 & 437 \\
7 & 415 & 167 & 357 \\
10 & 240 & 350 & 261 \\
12 & 39 & 277 & 85 \\
15 & 3 & 157 & 14 \\
20 & 0 & 21 & 0 \\
\hline
\end{tabular}

Table 3. Patron's acceptable wait times by hour of the day.

\begin{tabular}{|c|c|c|c|c|c|c|c|c|c|c|c|}
\hline \multirow{2}{*}{ \# Minutes } & \multicolumn{3}{|c|}{$\mathrm{AM}$} & \multicolumn{5}{|c|}{ MID } & \multicolumn{3}{|c|}{ PM } \\
\hline & 7 & 8 & 9 & 10 & 11 & 12 & 13 & 14 & 16 & 17 & 18 \\
\hline 2 & 0 & 2 & 0 & 0 & 0 & 0 & 0 & 0 & 0 & 0 & 0 \\
\hline 3 & 6 & 6 & 1 & 0 & 1 & 2 & 0 & 0 & 10 & 5 & 1 \\
\hline 5 & 172 & 154 & 83 & 19 & 34 & 26 & 28 & 14 & 180 & 166 & 91 \\
\hline 7 & 163 & 177 & 75 & 40 & 34 & 33 & 44 & 16 & 138 & 152 & 67 \\
\hline 10 & 89 & 97 & 54 & 73 & 90 & 81 & 79 & 27 & 109 & 102 & 50 \\
\hline 12 & 20 & 11 & 8 & 63 & 50 & 72 & 59 & 33 & 33 & 33 & 19 \\
\hline 15 & 2 & 1 & 0 & 39 & 26 & 40 & 31 & 21 & 6 & 8 & 0 \\
\hline 20 & 0 & 0 & 0 & 6 & 5 & 5 & 2 & 3 & 0 & 0 & 0 \\
\hline
\end{tabular}




\subsection{Acceptable Wait Times by Bus Stop Type}

The maximum acceptable wait times were reported by bus stop type in this section. Table 4 presents the summary of the maximum acceptable wait times by bus stop type. From the table, it can be observed that most patrons at bus stops without a bench chose shorter maximum acceptable wait times (5 to 10 minutes) compared to those at bus stops with a bench (7 to 12 minutes).

\subsection{Acceptable Wait Times by Gender}

This section presents the maximum acceptable wait times by gender. The summary of the maximum acceptable wait times by gender is presented in Table 5 . From the table, most female patrons picked 5 minutes as their maximum acceptable wait time, while male patrons picked 7 minutes.

\subsection{Acceptable Wait Times by Ethnicity}

The maximum acceptable wait times reported by ethnicity are presented in this section. The summary of the acceptable wait times by ethnicity is presented in Table 6. From the table, it can be observed that most white patrons chose $5 \mathrm{mi}$ nutes as their maximum acceptable wait times, while black and Asian patrons chose 7 minutes. Most Hispanic and "Other" ethnicity patrons chose the longer maximum acceptable wait time (10 minutes).

\subsection{Acceptable Wait Times by Knowledge of Bus Arrival Time}

The maximum acceptable wait times reported by knowledge of bus arrival time are presented in this section. The summary of the acceptable wait times by knowledge of bus arrival time is presented in Table 7. From the table, most patrons who knew the bus arrival time were more likely to wait shorter time periods (between 5 and 7 minutes) compared to those who did not know (between 10 to 12 minutes).

Table 4. Patron's acceptable wait times by hour of the day.

\begin{tabular}{ccc}
\hline \multirow{2}{*}{ \# Minutes } & \multicolumn{3}{c}{ Presence of Bench } \\
\cline { 2 - 3 } 2 & Yes & No \\
\hline 3 & 0 & 2 \\
5 & 3 & 29 \\
7 & 322 & 645 \\
10 & 508 & 431 \\
12 & 431 & 420 \\
15 & 260 & 141 \\
20 & 122 & 52 \\
\hline
\end{tabular}


Table 5. Patron's acceptable wait times by gender.

\begin{tabular}{ccc}
\hline \multirow{2}{*}{ \# Minutes } & \multicolumn{2}{c}{ Gender } \\
\cline { 2 - 3 } & Female & Male \\
\hline 2 & 2 & 0 \\
3 & 19 & 13 \\
5 & 513 & 454 \\
7 & 480 & 459 \\
10 & 415 & 436 \\
12 & 225 & 176 \\
15 & 87 & 87 \\
20 & 11 & 10 \\
\hline
\end{tabular}

Table 6. Patron's acceptable wait times by ethnicity.

\begin{tabular}{cccccc}
\hline \multirow{2}{*}{ \# Minutes } & \multicolumn{5}{c}{ Ethnicity } \\
\cline { 2 - 6 } & White & Black & Hispanic & Asian & Other \\
\hline 2 & 0 & 0 & 1 & 0 & 1 \\
3 & 12 & 5 & 9 & 2 & 4 \\
5 & 379 & 185 & 187 & 118 & 98 \\
7 & 152 & 266 & 174 & 195 & 152 \\
10 & 114 & 176 & 233 & 136 & 192 \\
12 & 86 & 93 & 98 & 59 & 65 \\
15 & 30 & 40 & 42 & 31 & 31 \\
20 & 5 & 6 & 3 & 4 & 3 \\
\hline
\end{tabular}

Table 7. Patron's acceptable wait times by knowledge of bus arrival time.

\begin{tabular}{ccc}
\hline \multirow{2}{*}{ \# Minutes } & \multicolumn{3}{c}{ Knowledge of Bus Arrival Time } \\
\cline { 2 - 3 } & Yes & No \\
\hline 2 & 2 & 0 \\
3 & 32 & 0 \\
5 & 943 & 24 \\
7 & 577 & 362 \\
10 & 483 & 368 \\
12 & 22 & 379 \\
15 & 9 & 165 \\
20 & 0 & 21 \\
\hline
\end{tabular}

\subsection{Acceptable Wait Times by Alternative Mode of Transportation}

In this section, the maximum acceptable wait times reported by patrons' alternate mode of transportation are presented. The summary of the acceptable wait 
times by choice of alternative mode of transportation is presented in Table 8. From the table, most patrons chose train and rideshare as their alternative mode of transportation after waiting between 5 and 10 minutes.

\subsection{Acceptable Wait Times by Temperature}

Table 9 presents the summary of responses of preferred maximum acceptable wait times by weather temperature at the time of the survey. From the table, it can be observed that patrons were more likely to choose longer maximum acceptable wait times as temperature increased.

\subsection{Summary of Acceptable Wait Times}

The mean acceptable wait times are presented in Table 10. The least mean wait times were reported during the morning period, at bus stops without bench, by female and White patrons and by patrons with knowledge of the bus arrival time.

\section{Discussions}

The research aimed at obtaining the maximum acceptable wait time of bus patrons based on the weather condition (temperature), gender, patrons' knowledge of bus arrival time and the presence of bench at the bus stops. Previous literature showed factors that affect the wait time of patrons included bus stop features and surroundings, period of day, the purpose of trip, and the patrons' demographics.

The data used in this study was obtained by surveying 3387 bus patrons at 71 selected bus stops within the District of Columbia over a 9 months period. Data obtained from patrons included their ethnicity, gender, maximum acceptable wait times (beyond the scheduled bus arrival time), alternate transportation mode choice, and knowledge of bus arrival times. In addition, information and conditions at each bus stop at the time of each survey were recorded. These included shelter and the temperature at the bus stop at the time of survey.

Table 8. Patron's acceptable wait times by alternative mode of transportation.

\begin{tabular}{cccccc}
\hline \multirow{2}{*}{ \# Minutes } & \multicolumn{5}{c}{ Alternative Mode of Transportation } \\
\cline { 2 - 6 } & Ride Share & Bike & Train & Walk & Other \\
\hline 2 & 0 & 0 & 1 & 1 & 0 \\
3 & 12 & 7 & 7 & 3 & 3 \\
5 & 301 & 76 & 279 & 142 & 169 \\
7 & 220 & 88 & 281 & 169 & 181 \\
10 & 160 & 143 & 238 & 119 & 191 \\
12 & 61 & 57 & 102 & 77 & 104 \\
15 & 52 & 11 & 21 & 26 & 64 \\
20 & 4 & 4 & 8 & 2 & 3 \\
\hline
\end{tabular}


Table 9. Patron's acceptable wait times by temperature.

\begin{tabular}{cccccccc}
\hline \multirow{2}{*}{ \# Minutes } & \multicolumn{7}{c}{ Temperature } \\
\cline { 2 - 8 } & $\mathbf{3 0 ^ { \circ } \mathrm { F } -}$ & $\mathbf{4 0 ^ { \circ } \mathrm { F } -}$ & $\mathbf{5 0 ^ { \circ } \mathrm { F } -}$ & $\mathbf{6 0 ^ { \circ } \mathrm { F } -}$ & $\mathbf{7 0 ^ { \circ } \mathrm { F } -}$ & $\mathbf{8 0 ^ { \circ } \mathrm { F } -}$ & $\mathbf{9 0 ^ { \circ } \mathrm { F } -}$ \\
\hline $\mathbf{3 9 ^ { \circ } \mathrm { F }}$ & $\mathbf{4 9 ^ { \circ } \mathrm { F }}$ & $\mathbf{5 9 ^ { \circ } \mathrm { F }}$ & $\mathbf{6 9 ^ { \circ } \mathrm { F }}$ & $\mathbf{7 9 ^ { \circ } \mathrm { F }}$ & $\mathbf{8 9 ^ { \circ } \mathrm { F }}$ & $\mathbf{9 9 ^ { \circ } \mathrm { F }}$ \\
\hline $\mathbf{5}$ & 13 & 10 & 1 & 8 & 0 & 0 & 0 \\
7 & 53 & 265 & $\mathbf{2 3 8}$ & 207 & 186 & 18 & 0 \\
10 & 0 & 0 & $\mathbf{2 3 8}$ & $\mathbf{6 5 1}$ & 50 & 0 & 0 \\
12 & 0 & 2 & 9 & 269 & $\mathbf{4 5 1}$ & 120 & 0 \\
$\mathbf{1 5}$ & 0 & 0 & 7 & 10 & 189 & 185 & 10 \\
$\mathbf{2 0}$ & 0 & 0 & 1 & 11 & 0 & 149 & 13 \\
\hline
\end{tabular}

Table 10. Patron's mean acceptable wait times.

\begin{tabular}{ccc}
\hline & Category & Avg. Acceptable Wait Time (Minutes) \\
\hline Time of Day & AM & 7.0 \\
& MID & 10.5 \\
Presence of Bench & Without Bench & 7.5 \\
Wender & With Bench & 7.5 \\
& Male & 9.0 \\
& Female & 8.5 \\
Ethnicity & White & 8.0 \\
& Black & 7.0 \\
& Hispanic & 8.5 \\
Knowledge of Bus & Asian & 8.3 \\
Arrival Time & Other & 8.4 \\
& No & 8.5 \\
\hline & Yes & 10.5 \\
\hline
\end{tabular}

The results of the analysis of the survey data obtained showed that most patrons' acceptable wait times ranged from 5 to 15 minutes. The maximum acceptable wait time of patrons during the mid-day period was found to be higher than during the morning and evening peak periods that corroborates the finding in previous literature (Psarros et al.). The least acceptable wait time was recorded during the morning peak period. This could be explained by the fact that most patrons are most likely to be commuting to work and need to arrive on time. The mean acceptable wait times of patrons waiting at bus stops with bench was approximately $28 \%$ higher than mean acceptable wait times of patrons at bus stops without shelter. However, with regards to gender, the mean maximum acceptable wait times of male and female patrons were approximately equal. This 
gives an indication that the gender of a patron does not determine their waiting tolerance level. Further, in terms of race, white patrons reported the lowest mean maximum acceptable wait time, while Black and "other" patrons recorded the highest of that variable. Hispanic and Asian patrons had approximately the same average acceptable wait times. Also, bus patrons who had knowledge of the arrival time of the bus were observed to have lower acceptable wait times compared to those who had no knowledge of the arrival time. Patrons with knowledge of the arrival time of buses, tend to be less tolerant when buses do not arrival as scheduled. Forty percent $(40 \%)$ of the patrons surveyed considered using a train as an alternate transportation mode while about 35\% considered using Ride Share. Patrons at bus stops close to train stations mostly preferred using a train. Also, $10 \%$ preferred to walk to their destination if it is within a walking distance. In addition, $11 \%$ of the patrons preferred to use a bicycle.

\section{Conclusion and Recommendations}

The trends observed in the data suggest that the improvement of bus stop facilities increases the waiting tolerance of bus patrons. Thus, the data obtained from the survey is potentially useful information that transit agencies could use to improve bus scheduling and operations to ultimately retain and improve ridership.

\section{Conflicts of Interest}

The authors declare no conflicts of interest regarding the publication of this paper.

\section{References}

[1] Hensher, D. and Golob, T. (2008) Bus Rapid Transit Systems: A Comparative Assessment. Transportation, 35, 501-518. https://doi.org/10.1007/s11116-008-9163-y

[2] Ben-Akiva, M. and Lerman, S.R. (1985) Discrete Choice Analysis: Theory and Application to Travel Demand. MIT Press, Cambridge, MA.

[3] Durán-Hormazábal, E. and Tirachini, A. (2016) Estimation of Travel Time Variability for Cars, Buses, Metro and Door-to-Door Public Transport Trips in Santiago, Chile. Transportation Economics, 59, 26-39. https://doi.org/10.1016/j.retrec.2016.06.002

[4] Mishalani, R.G., et al. (2006) Passenger Wait Time Perceptions at Bus Stops: Empirical Results and Impact on Evaluating Real-Time Bus Arrival Information. Journal of Public Transportation, 9, 89-106. https://doi.org/10.5038/2375-0901.9.2.5

[5] Wardman, M. (2004) Public Transport Values of Time. Transport Policy, 11, 363-377. https://doi.org/10.1016/j.tranpol.2004.05.001

[6] Horowitz, A. (1981) Subjective Value of Time in Bus Transit Travel. Transportation, 10, 149-164. https://doi.org/10.1007/BF00165263

[7] Moreau, A. (1992) Public Transport Waiting Times as Experienced by Customers. Public Transport International, 41, 52-71.

[8] Van Hagen, M. (2011) Waiting Experience at Train Stations. Doctoral Dissertation, 
Eburon Uitgeverij BV.

[9] Fan, Y.L., Guthrie, A. and Levinson, D. (2016) Waiting Time Perceptions at Transit Stops and Stations: Effects of Basic Amenities, Gender, and Security. Transportation Research Part A, 88, 251-264.

[10] Psarros, I., Kepaptsoglou, K. and Karlaftis, M.G. (2011) An Empirical Investigation of Passenger Wait Time Perceptions Using Hazard-Based Duration Models. Journal of Public Transportation, 14, 109-122. https://doi.org/10.5038/2375-0901.14.3.6

[11] Feng, S., Wu, H., Sun, X. and Li, Z. (2015) Factors of Perceived Waiting Time and Implications on Passengers' Satisfaction with Waiting Time. Promet-Traffic \& Transportation, 28. https://doi.org/10.7307/ptt.v28i2.1726

[12] Turnquist, M.A. and Bowman, L.A. (1979) Service Frequency, Schedule Reliability and Passenger Wait Times at Transit Stops. Transportation Research Part A: General, 15, 465-471. https://doi.org/10.1016/0191-2607(81)90114-X

[13] Yang, M., Zhao, J., Wang, W., Liu, Z. and Li, Z. (2014) Metro Commuters' Satisfaction in Multi-Type Access and Egress Transferring Groups. Transportation Research Part D: Transport and Environment, 34, 179-194.

https://doi.org/10.1016/j.trd.2014.11.004

[14] Stover, V. and McCormack, E. (2012) The Impact of Weather on Bus Ridership in Pierce County, Washington. Journal of Public Transportation, 15, 95-110. https://doi.org/10.5038/2375-0901.15.1.6

[15] Susan, H., Clifton, K. and Fisher, J. (1998) The Effectiveness of Land Use Policies as a Strategy for Reducing Automobile Dependence: A Study of Austin Neighborhoods. Research Report SWUTC/98/467501-1. University of Texas Press, Austin, TX.

[16] Nam, D., Park, D. and Khamkongkhun, A. (2005) Estimation of Value of Travel Time Reliability. Journal of Advanced Transportation, 39, 39-61. https://doi.org/10.1002/atr.5670390105

[17] Han, Y., Li, W., Wei, S. and Zhang, T. (2018) Research on Passenger's Travel Mode Choice Behavior Waiting at Bus Station Based on SEM-Logit Integration Model. Sustainability, 10, 1996. https://doi.org/10.3390/su10061996

[18] Xue, Y., Zhang, Z., Guan, H. and Qin, H. (2013) A Traffic Mode Choice Model for the Bus User Groups Based on SP and RP Data. Procedia-Social and Behavioral Sciences, 96, 382-389.

[19] Train, K. (2003) Discrete Choice Methods with Simulation. Cambridge University Press, Cambridge. https://doi.org/10.1017/CBO9780511753930 